\title{
FORMULASI DAN EVALUASI FISIK KRIM KOSMETIK DENGAN VARIASI EKSTRAK KAYU SECANG (Caesalpinia sappan) DAN BEESWAX SUMBAWA
}

\author{
Samuyus Nealma ${ }^{1}$, Nurkholis ${ }^{2}$ \\ $1^{*}$ Fakultas Teknologi Pertanian Universitas Teknologi Sumbawa \\ 2Program Studi Teknologi Industri Pertanian Universitas Teknologi Sumbawa \\ *Corresponding Author email: \\ 1samuyus.nealma@uts.ac.id, ${ }^{2}$ nurkholis@uts.ac.id
}

\begin{tabular}{|c|c|}
\hline & bstrak \\
\hline $\begin{array}{l}\text { Diterbitkan } \\
\text { Bulan Juli } 2020 \\
\text { Keyword : } \\
\text { Formulasi, krim, } \\
\text { Evaluasi Fisik, } \\
\text { Secang, Lilin } \\
\text { Lebah. }\end{array}$ & $\begin{array}{l}\text { Dalam penelitian ini, kayu secang akan digunakan dalam bentuk krim menggunakan } \\
\text { basis lilin lebah Sumbawa. Tujuan dari penelitian ini adalah untuk mendapatkan } \\
\text { formulasi krim terbaik dengan ekstrak kayu secang dan lilin lebah. Formula krim } \\
\text { didasarkan pada konsentrasi ekstrak secang } 0,5-2,5 \text { gram dan lilin lebah } 0,2-4 \text { gram } \\
\text { dalam } 20 \text { gram sediaan. Penentuan evaluasi fisik akan dilakukan beberapa tes, yaitu uji } \\
\text { organoleptik, pH, daya lekat, daya sebar dan daya lindung. Hasil penelitian } \\
\text { menunjukkan bahwa ketiga formula, Formulasi } 1 \text { (F1) dan F3 adalah homogen, } \\
\text { sedangkan F2 tidak homogen. Dalam pengujian pH, semua formulasi } 1,2 \text { dan } 3 \\
\text { memiliki pH rata-rata } 6 \text {. Dan dalam pengujian organoleptik, F3 menunjukkan skor } 3,9 \\
\text { dalam bentuk dan merupakan yang tertinggi dibandingkan dengan dua formulasi } \\
\text { lainnya, F1 memiliki skor } 2,8 \text {, F2 skor } 2.2 \text {. Sedangkan pada organoleptik warna, skor } \\
\text { tertinggi adalah F3 dengan skor } 3,8 \text {, skor F1 } 2,8 \text { dan skor F3 2,2. Dan dalam } \\
\text { organoleptik tidak berbau, F1 memiliki skor tertinggi 3,6, skor F3 3,3 dan skor F2 2,7. } \\
\text { Dalam uji daya sebar, F1 memiliki nilai rata-rata } 11,8, \text { F2 dengan nilai } 53,52 \text { dan F3 } \\
\text { dengan nilai } 11,68 \text {. Tes adhesi F1, F2 dan F3 masing-masing memiliki nilai } 2,3 \text { detik, } \\
\text { 2,3 dan } 3,67 \text {. Dan dalam pengujian perlindungan KOH semua formula menunjukkan } \\
\text { perubahan. }\end{array}$ \\
\hline
\end{tabular}

\section{PENDAHULUAN}

Secang (Caesalpinia sappan) tumbuh liar di daerah pegunungan yang berbatu, tetapi tidak terlalu dingin dan biasanya ditanam sebagai pembatas ladang. Tanaman ini dapat ditemukan sampai ketinggian $1000 \mathrm{~m}$ di atas permukaan laut.Di Pulau Sumbawa keberadaan tanaman ini sangat melimpah, hal ini didukung dengan kondisi wilayah Sumbawa yang berbukitbukit dan dikelilingi pengunungan berbatu.Sejarah mencatat bahwa pada masa Hindia Belanda, wilayah Sumbawa menjadi daerah pemasok kayu secang ke Eropa yang digunakan sebagai bahan pewarna merah alami.

Di berbagai daerah Indonesia, kayu secang dimanfaatkan sebagai pewarna merah minuman. Kayu dan batangnya dapat mengobati TBC, diare dan disentri. Kayu secang juga berkhasiat mengaktifkan airan darah, melarutkan gumpalan darah, mengurangi bengkak (swelling), meredakan nyeri (analgesik), menghentikan perdarahan dan antiseptik (Dalimartha, 2009). Kayu secang secara tradisional telah digunakan oleh masyarakat Sumbawa untuk perawatan kulit. Hasil penelitian juga menyebutkan bahwa ekstrak etanol 50\% kayu secang baik sebagai antijerawat berdasarkan aktivitas antibakteri $P$. acnes, inhibitor lipase dan antioksidan dengan senyawa aktifnya adalah brazilin (Batubara, dkk., 2009).

Lilin lebah merupakan hasil sampingan dari usaha madu. Sumbawa menjadi salah satu daerah yang dikenal sebagai penghasil madu hutan terbaik di Indonesia. Selama ini pemanfaatan hasil sampingan berupa lilin lebah belum banyak dilakukan. Dalam peningkatan nilai guna hasil sampingan ini, maka lilin lebah sangat berpotensi menjadi bahan dalam pembuatan krim. Lilin lebah merupakan lilin yang kimianya stabil, dengan penggunaan 
terbanyak untuk kosmetik. Lilin lebah dimanfaatkan dalam formulasi krim karena merupakan bahan yang tidak iritan ketika kontak dengan kulit. Penambahan lilin lebah dalam formulasi krim tangan dan badan dapat memperbaiki viskositas dan stabilitas emulsi.

Pada penelitian ini, ekstrak kayu secang akan dimanfaatkan dalam bentuk sediaan krim dengan menggunakan basis lilin lebah madu hutan Sumbawa. Krim didefinisikan sebagai cairan kental atau emulsi setengah padat baik bertipe air dalam minyak maupun minyak dalam air.Krim biasanya digunakan sebagai emolien atau pemakaian obat pada kulit. Sediaan krim dipilih karena sifatnya mudah menyebar rata, mudah dibersihkan, serta aman bila digunakan oleh anak-anak maupun dewasa, praktis dalam pemakaiaannya, cara kerja berlangsung pada jaringan setempat, dapat digunakan sebagai kosmetik, bahan untuk pemakaian topikal (Syamsuri, 2006).

\section{METODE PENELITIAN}

\section{Tempat Penelitian}

Penelitian ini akan dilaksanakan di Laboratorium Pangan Terpadu, Fakultas Teknologi Pertanian, Universitas Teknologi Sumbawa dan Laboratorium Farmasi Universitas Katolik Widya Mandala Surabaya .

\section{Bahan dan Alat}

Bahan utama yang digunakan dalam penelitian ini adalah kayu secang (caesalpinia sappan L.) Bahan kimia yang digunakan untuk membuat krim kosmetikyaitu asam stearat, beeswax, vaselin albi, triethanolamine(TEA), propylene glycol, nipagin, aquadest dan $\mathrm{KOH}$.

Alat yang digunakan dalam penelitian ini meliputi: blender, bejana, pengaduk,cawan porselen, penangas air (waterbath), rheoviscometer, extensiometer, dan kertas saring.

\section{Metode Penelitian}

\section{Kayu Secang}

Kayu secang diperoleh dari desa usar mapin kecamatan alas barat kabupaten Sumbawa. Kayu Secang selanjutnya dikuliti dan diserut sehingga menghasilkan serutanserutan kayu, yang kemudian dikeringkan dengan suhu $\pm 60{ }^{\circ} \mathrm{C}$ selama 5 menit dan diperkecil. Serbuk kayu kering dijadikan bahan untuk diekstrak.

2. Pembuatan ekstrak secang

Pembuatan ekstrak secang dengan metode maserasi. Serbuk secang sebanyak 100gr dimasukkan ke dalam bejana dan ditambahkan $250 \mathrm{ml}$ pelarut etanol dan lalu diaduk. Direndam selama 5 hari sambil terus dilakukan pengadukan. Kemudian ampas diperas dan diuapkan menggunakan kompor dan panci yang berisi air $\pm 100 \mathrm{ml}$ dengan suhu $80{ }^{\circ} \mathrm{C}$.

3. Formulasi

Pembuatan formulasi dengan melakukan penimbangan bahan-bahan yang akan digunakan pada pembuatan krim. Pada proses pembuatan krim, formula dasar yang digunakan adalah modifikasi dari formula dan proses pembuatan produk krim Liebermen (1996).

Tabel 3.Formula Krim Ekstrak Secang dan beeswax Sumbawa

\begin{tabular}{|c|c|c|c|}
\hline Bahan & F1 & F2 & F3 \\
\hline Ekstrak & $2,5 \mathrm{gr}$ & $1,5 \mathrm{gr}$ & $0,5 \mathrm{gr}$ \\
\hline \multicolumn{4}{|l|}{ Kayu } \\
\hline \multicolumn{4}{|l|}{ Secang } \\
\hline Asam & $3 \mathrm{gr}$ & $3 \mathrm{gr}$ & $3 \mathrm{gr}$ \\
\hline \multicolumn{4}{|l|}{ Stearat } \\
\hline Beeswax & $2 \mathrm{gr}$ & $3 \mathrm{gr}$ & $4 \mathrm{gr}$ \\
\hline $\begin{array}{l}\text { Vaselin } \\
\text { album }\end{array}$ & $4 \mathrm{gr}$ & $4 \mathrm{gr}$ & $4 \mathrm{gr}$ \\
\hline TEA & $0,3 \mathrm{gr}$ & $0,3 \mathrm{gr}$ & $0,3 \mathrm{gr}$ \\
\hline Propilen & $1,6 \mathrm{gr}$ & $1,6 \mathrm{gr}$ & $1,6 \mathrm{gr}$ \\
\hline \multicolumn{4}{|l|}{ Glikol } \\
\hline Nipagin & $0,75 \mathrm{gr}$ & $0,75 \mathrm{gr}$ & $0,75 \mathrm{gr}$ \\
\hline Aquadest & ad $20 \mathrm{ml}$ & ad $20 \mathrm{ml}$ & ad $20 \mathrm{ml}$ \\
\hline
\end{tabular}


4. Evaluasi Fisik

a. Uji Homogenitas

Dilakukan dengan menggunakan kaca transparan. Krim ditimbang 1 gr, kemudian dioleskan pada kaca. Sediaan krim harus menunjukkan susunan yang homogen dan tidak terlihat adanya butiran kasar dan menggumpal (Lubis dkk, 2012).Uji homogenitas bertujuan untuk melihat dan mengetahui tercampurnya bahan-bahan sediaan krim.

b. Uji pH

Penentuan $\mathrm{pH}$ dilakukan dengan menggunakan kertas lakmus. Krim di timbang $1 \mathrm{gr}$ dan di larutkan dengan $1 \mathrm{ml}$ aquades lalu celupkan kertas lakmus hingga menunjukkan hasil $\mathrm{pH}$ tersebut. Pengukuran dilakukan sebanyak tiga kali untuk masingmasing sediaan pada saat sediaan dibuat dan penyimpanan selama 3 minggu.

c. Uji Organoleptik

Pemeriksaan terhadap organoleptik dilakukan meliputi bentuk, warna dan bau yang diamati menggunakan panelis.Panelis yang melakukan pengamatan yaitu panelis tidak terlatih sebanyak 30 orang. Spesifikasi krim yang harus dipenuhi adalah memiliki konsistensi lembut, warna sediaan homogen, dan baunya harum dari masing-masing krim.

d. Uji Daya Lengket

Dilakukan dengan menggunakan alat rheviscometer, dan bertujuan untuk mengetahui kemampuan krim melekat pada kulit.

e. Uji Daya Sebar

Uji daya sebar dilakukan dengan menggunakan extensiometer.

f. Uji Daya Proteksi

Uji daya proteksi dilakukan dengan $\mathrm{KOH} 0,1 \mathrm{~N}$ yang diteteskan pada kertas saring.

\section{HASIL DAN PEMBAHASAN}

\subsection{Ekstraksi Kayu Secang}

Ekstraksi kayu secang dilakukan dengan menggunakan 100 gr serbuk secang kering dimaserasi dengan pelarut etanol sebanyak $250 \mathrm{ml}$, kemudian direndam selama
5 hari sambil sesekali diaduk, setelah 5 hari didiamkan kemudian disaring dengan menggunakan kertas saring sehingga didapat filtrat. Filtrat yang telah dihasilkan kemudian diuapkan pada suhu $80{ }^{\circ} \mathrm{C}$ hingga diperoleh ekstrak. Ekstrak secang yang diperoleh yaitu sebanyak $100 \mathrm{ml}$.

\subsection{Evaluasi Fisik Sediaan Krim}

\section{a. Homogenitas Krim}

Pengujian homogenitas sediaan krim bertujuan untuk melihat dan mengetahui tercampurnya bahan-bahan sediaan krim, seperti zat aktif, fase minyak dan fase air (Juwita, 2013). Pengamatan homogenitas fisik krim pada F1, F2 dan F3 dilakukan selama 1 hari dalam 3 minggunya, hasil pengamatan ketiga formula krim hanya F2 tidak mengalami proses homogen karena ditemukan adanya butiran-butiran kasar didalam krim. Hal ini menunjukkan bahwa sediaan krim pada F2 tidak stabil karena didalam kandungan F2 mengandung fase minyak dan fase air yang sama yang menyebabkan ketidakstabilan emulsi yang terbentuk diakibatkan proses pengadukan yang tidak sempurna yang menyebabkan terjadinya proses pecahnya emulsi yang bersifat tidak dapat kembali (Hisprastin dan Nuwarda, 2018). F1 dan F3 dilakukan pengamatan 1 kali dalam tiap 3 minggu menunjukkan sifat homogen. Hal ini menunjukkan bahwa bahan-bahan dalam pembuatan krim sudah tercampur dengan baik. Krim yang memenuhi syarat homogenitas fisik yaitu tidak terlihat partikel kasar, yaitu jika dioleskan pada sekeping kaca tidak adanya partikel dan pemisahan antara komponen penyusun emulsi tersebut (Erungan, 2009). F2 hingga minggu ke-3 semakin terlihat jelas tidak homogen karena terlihat menggumpal dan cairan minyak yang memisah. Dapat dilihat pada tabel 1.

Tabel 1. Hasil Pengamatan Homogenitas Fisik Krim. 


\begin{tabular}{lccc}
\hline Formula & \multicolumn{3}{c}{ Homogenitas fisik } \\
\cline { 2 - 4 } & Mgg ke-1 & Mgg ke-2 & Mgg ke-3 \\
\hline 1 & + & + & + \\
2 & - & - & - \\
3 & + & + & + \\
\hline
\end{tabular}

Keterangan :(+) homogen, (-) tidak homogen

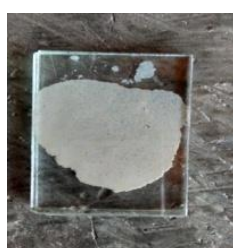

F1

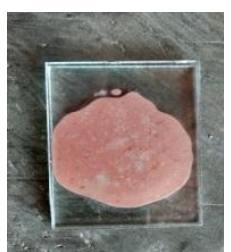

$\mathrm{F} 2$

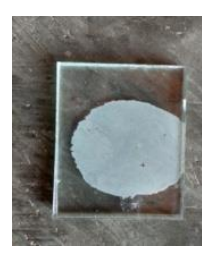

F3
Gambar 1. Pengamatan Homogenitas Krim

\section{b. Uji pH Sediaan Krim}

Uji pH dilakukan menggunakan kertas lakmus untuk mengetahui sediaan krim yang sesuai dengan $\mathrm{pH}$ kulit 4,5-6,5 agar sediaan krim tidak mengiritasi kulit saat digunakan. Pengukuran $\mathrm{pH}$ ini bertujuan untuk mengetahui apakah krim yang telah dibuat bersifat asam atau basa karena $\mathrm{pH}$ kulit wajah memiliki kriteria yaitu sekitar 4,5-6,5 sehingga aman dalam penggunaan dan tidak mengiritasi kulit (Tranggono dan Latifah, 2007). Untuk krim pada F1,F2 dan F3 didapatkan hasil $\mathrm{pH}$ sebesar 6 yang bersifat lebih asam. Nilai pH yang kurang dari 4,5 dapat mengiritasi kulit sementara $\mathrm{pH}$ yang melebihi 6,5 dapat membuat kulit menjadi bersisik (Sharon, et al., 2013). Hasil uji pH krim ekstrak secang dapat dilihat pada tabel 2 dibawah ini.

Tabel 2. Hasil Uji pH Sediaan Krim

\begin{tabular}{rrrr}
\hline & \multicolumn{3}{c}{ Derajat Keasaman $(\mathrm{pH})$} \\
\cline { 2 - 4 } Formulasi & $\begin{array}{c}\text { Minggu } \\
\text { ke-1 }\end{array}$ & $\begin{array}{c}\text { Minggu } \\
\text { ke-2 }\end{array}$ & $\begin{array}{c}\text { Minggu } \\
\text { ke-3 }\end{array}$ \\
\hline F1 & 6 & 6 & 6 \\
F2 & 6 & 6 & 6 \\
F3 & 6 & 6 & 6 \\
\hline
\end{tabular}

Berdasarkan hasil pengujian $\mathrm{pH}$ ketiga formula sediaan krim diketahui bahwa $\mathrm{pH}$ rata-rata krim adalah 6 . Nilai $\mathrm{pH}$ tersebut berada dalam kisaran nilai $\mathrm{pH}$ yang terdapat pada SNI 16-4399-1996 sebagai syarat mutu pelembab kulit $(4,5-8,0)$ dan kisaran $\mathrm{pH}$ normal kulit yaitu 4,5-6,5 (Rizky dkk., 2013). Dengan demikian krim yang dihasilkan relatif aman digunakan. Hal ini menunjukkan bahwa krim yang dibuat memenuhi syarat $\mathrm{pH}$ kulit yaitu 4,5-6,5 sehingga aman untuk diaplikasikan ke kulit. $\mathrm{pH}$ sediaan harus berada dalam rentang $\mathrm{pH}$ kulit untuk mencegah iritasi pada kulit (Safitri dkk., 2014).

\section{c. Uji Organoleptik}

Pengujian organoleptik sediaan krim menunjukkan bahwa ketiga formulasi memiliki karakteristik yang berbeda yaitu dari bentuk, warna dan bau. Bentuk dari F1 semi padat, memiliki warna orange kecoklatan dan memiliki bau khas secang. Bentuk dari F2 agak cair, memiliki warna orang kemerahan dan memiliki bau khas secang dan beeswax. Bentuk F3 semi padat, memiliki warna orange muda, dan memiliki bau khas beeswax. F3 memiliki warna orange muda namun bentuknya padat dan memiliki bau khas secang namun tidak berbau tengik dan memiliki bentuk yang lembut serta tidak lengket ketika diaplikasikan ke kulit. Krim yang disukai oleh masyarakat adalah krim yang berbentuk lembut dan tidak memberikan rasa lengket agar terasa lebih nyaman untuk diaplikasikan ke kulit tubuh (Christina, 2009). Setelah pengamatan minggu pertama maka di lanjutkan pengamatan organoleptik untuk minggu ke-2 dan minggu ke-3 dari ketiga formula tidak mengalami perubahan bentuk, warna, dan bau seperti pada minggu yang ke-1.Warna yang dimunculkan pada krim berasal dari brazilin sebagai kandungan utama ekstrak secang yang memberikan khasiat sebagai antibakteri (Yulyuswarni, 2019). Hal ini menunjukkan bahwa hanya F2 yang tidak menunjukkan kestabilan pada formula krim. Dapat dilihat pada tabel 3 
Tabel 3. Hasil Pengamatan Organoleptik Krim

\begin{tabular}{|c|c|c|c|c|}
\hline \multirow[t]{2}{*}{ Penyimpanan } & \multirow[t]{2}{*}{ Formula } & \multicolumn{3}{|c|}{ Parameter } \\
\hline & & Bentuk & Warna & Bau \\
\hline \multirow[t]{3}{*}{ Minggu ke-1 } & F1 & Semi padat & $\begin{array}{l}\text { Orange } \\
\text { kecoklatan }\end{array}$ & Khas secang \\
\hline & $\mathrm{F} 2$ & Agak cair & $\begin{array}{l}\text { Orange } \\
\text { kemerahan }\end{array}$ & $\begin{array}{l}\text { Khas } \\
\text { beeswax + } \\
\text { secang }\end{array}$ \\
\hline & F3 & Semi padat & Orange muda & $\begin{array}{l}\text { Khas } \\
\text { beeswax }\end{array}$ \\
\hline \multirow[t]{3}{*}{ Minggu ke-2 } & $\mathrm{F} 1$ & Semi padat & $\begin{array}{l}\text { Orange } \\
\text { kemerahan }\end{array}$ & Khas secang \\
\hline & $\mathrm{F} 2$ & Agak cair & $\begin{array}{l}\text { Orange } \\
\text { kecoklatan }\end{array}$ & $\begin{array}{l}\text { Khas } \\
\text { beeswax + } \\
\text { secang }\end{array}$ \\
\hline & F3 & Semi padat & Merah muda & $\begin{array}{l}\text { Khas } \\
\text { beeswax }\end{array}$ \\
\hline \multirow[t]{3}{*}{ Minggu ke-3 } & $\mathrm{F} 1$ & Semi padat & $\begin{array}{l}\text { Orange } \\
\text { kemerahan }\end{array}$ & Khas secang \\
\hline & $\mathrm{F} 2$ & Agak cair & $\begin{array}{l}\text { Orange } \\
\text { kemerahan }\end{array}$ & $\begin{array}{l}\text { Khas } \\
\text { beeswax + } \\
\text { secang }\end{array}$ \\
\hline & F3 & Semi padat & Merah muda & $\begin{array}{l}\text { Khas } \\
\text { beeswax }\end{array}$ \\
\hline
\end{tabular}

Uji organoleptik dilakukan untuk mengetahui tingkat kesukaan panelis terhadap produk yang dihasilkan. Uji organoleptik meliputi uji kesukaan. Uji kesukaan dilakukan dengan cara mengukur, menilai, atau menguji mutu komoditas dengan menggunakan alat indera manusia yaitu penglihatan, penciuman dan peraba.

Uji kesukaan yang dilakukan yaitu dengan cara melihat produk, mencium dengan hidung, dan meraba produk dengan ujung jari kemudian mengoleskannya ke kulit. Dalam uji ini, panelis diminta untuk menilai produk sesuai dengan tingkat kesukaan terhadap krim kosmetik dengan skala numeric, 1 adalah sangat tidak suka; 2 adalah tidak suka; 3 adalah agak suka; 4 adalah suka; dan 5 adalah sangat suka. Halhal yang diuji meliputi bentuk, warna dan bau. Uji ini bersifat subjektif dan panelis yang melakukan pengujian merupakan panelis acak berjumlah 30 orang yang merupakan panelis panelis tidak terlatih.

\section{Bentuk}

Uji kesukaan berdasarkan parameter kesukaan terhadap bentuk sediaan krim

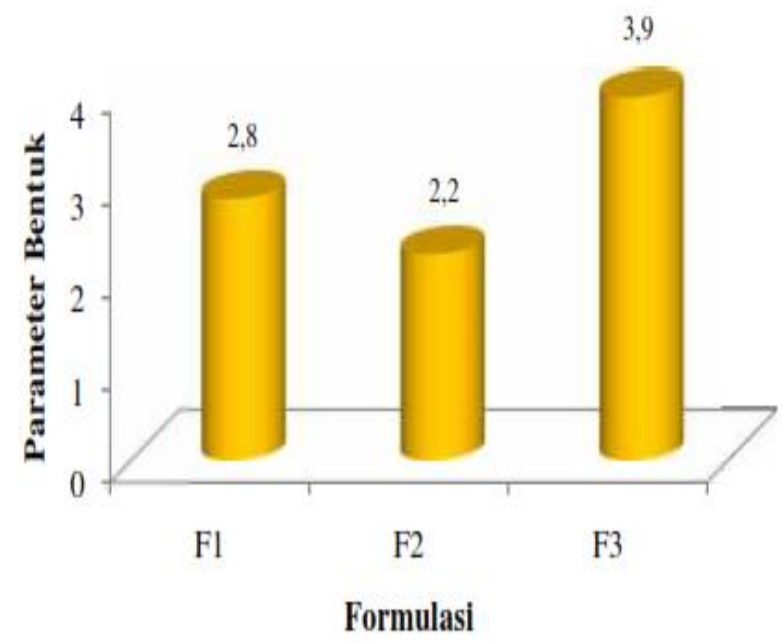

dengan cara menganalisa pendapat terhadap bentuk sediaan dengan berbagai konsentrasi. 
Gambar 1. Hasil Pengujian Organoleptik pada Parameter Bentuk

Dari gambar diatas dapat dilihat bahwa rerata skor yang diberikan oleh panelis terhadap bentuk sediaan krim kosmetik tertinggi adalah F3 yaitu 3,9 dan rerata skor yang terendah adalah F2 yaitu 2,2, hal ini disebabkan karena bentuk F2 tidak homogen karena masih terdapat gumpalan-gumpalan kasar pada sediaan krim.

Hasil uji ANOVA menunjukkan bahwa nilai F-hitung sebesar 25,06 dan signifikan pada 0,05 (sig=0,000<0,05). Hal ini dapat disimpulkan ada perbedaan hasil sediaan krim kosmetik. Perbedaan ini disebabkan oleh penambahan ekstrak secang dan beeswax pada masing-masing formulasi krim.

\section{Warna}

Hasil penelitian terhadap warna yang diujikan pada 30 panelis tentang produk krim kosmetik yang telah diberikan ekstrak kayu secang dan beeswax adalah ditunjukkan dalam gambar berikut.

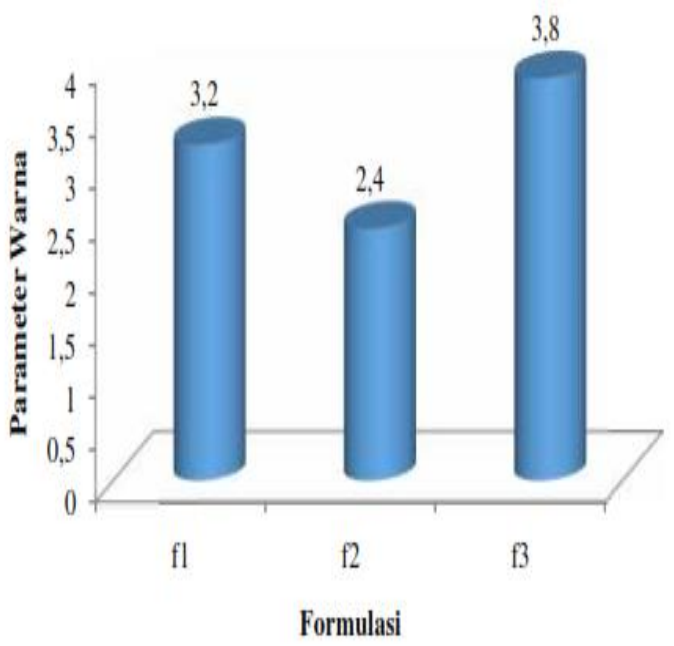

Gambar.2 Hasil Pengujian Organoleptik pada Parameter Warna

Hasil uji ANOVA menunjukkan bahwa nilai F-hitung sebesar 15,627 dan signifikan pada 0,05 (sig $=0,000<0,05)$. Hal ini dapat disimpulkan ada perbedaan pada organoleptik warna. Berdasarkan hasil uji kesukaan aspek warna pada krim paling tinggi pada F3 dengan penambahan ekstrak secang 0,5 gr dan beeswax $4 \mathrm{gr}$. warna yang dihasilkan yaitu orange muda. Krim yang identik pengunaannya oleh wanita cenderung menyukai warna lebih terang.

Warna orange memberi kesan hangat dan bersemangat. Warna ini merupakan simbol dari petualangan, optimisme, percaya diri dan kemampuan bersosialisasi (Zharandont, 2015).

Bau

Uji kesukaan terhadap bau krim dilakukan dengan meminta panelis untuk mencium bau dari setiap formulasi krim. Hasil ditunjukkan pada gambar dibawah ini.

Gambar 3. Hasil Pengujiaan

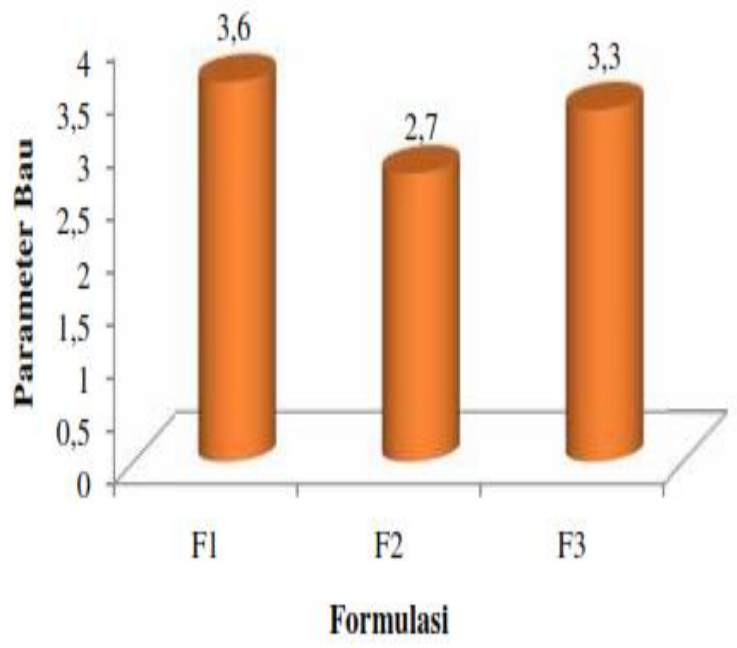

Organoleptik pada Parameter Bau

Hasil uji ANOVA menunjukkan bahwa F-hitung sebesar 5,486 dan signifikan pada $0,05 \quad(\operatorname{sig}=0,006<0,05)$. Hal ini dapat disimpulkan ada perbedaan hasil krim kosmetik pada aspek bau pada setiap formulasi. Berdasarkan hasil uji aspek bau F1 memiliki nilai tertinggi, dengan formulasi ekstrak secang 2,5 gr dan beeswax 2 gr dengan nilai 3,6. Bau krim yang dihasilkan berbau khas secang. Secang adalah tanaman yang tidak memiliki aroma menyengat, bahkan cenderung tidak beraroma. 


\section{Uji Daya Sebar}

Pengujian daya sebar dilakukan guna menunjukkan kemampuan krim menyebar pada lokasi penggunaan dan mengetahui kelunakan dari sediaan krim. Adapun uji daya sebar pada ketiga formulasi adalah sebagai berikut :

Tabel 5. Hasil Uji Daya Sebar

\begin{tabular}{ccc}
\hline Formulasi & $\begin{array}{c}\text { Berat Beban } \\
(\mathrm{gr})\end{array}$ & $\begin{array}{c}\text { Luas } \\
\left(\mathrm{cm}^{2}\right)\end{array}$ \\
\hline F1 & 20 & 5,55 \\
& 50 & 11,33 \\
F2 & 100 & 18,54 \\
& 20 & 28,83 \\
& 50 & 55,4 \\
F3 & 100 & 76,32 \\
& 20 & 7,06 \\
& 50 & 13,32 \\
& 100 & 14,65 \\
\hline
\end{tabular}

Berdasarkan uji daya sebar pada ketiga formulasi krim menunjukkan bahwa F2 memiliki daya sebar terluas dibandingkan F1 dan F3. Krim diharapkan mampu menyebar dengan sempurna tanpa ada kesulitan dalam pengggunaan pada kulit, sehingga dalam pengaplikasiaannya akan lebih luas daerah yang tersentuh oleh krim. Krim F2 memiliki konsistensi yang lebih cair. Kondisi cari menyebabkan krim mampu menyebar luas.

\section{Uji Daya Lekat}

Pengujian daya lekat untuk mengetahui krim menempel pada permukaan kulit sewaktu digunakan agar berfungsi maksimal. Kemampuan krim apabila melekat semakin lama pada kulit, maka zat aktif yang dilepaskan dari basisnya akan semakin banyak diabsorbsi melalui kulit.I

Tabel 6. Hasil Uji Daya Lekat Krim

\begin{tabular}{cc}
\hline Formula & Waktu lekat (dtk) \\
\hline F1 & 2,3 \\
F2 & 2,3 \\
F3 & 3,67 \\
\hline
\end{tabular}

Pada penelitian ini menunjukkan F1 dan F2 memiliki hasil yang sama dalam uji daya lekatnya yakni 2,3 detik, sementara F3 memiliki daya lekat selama 3,67 detik. Hal ini menunjukkan F3 lebih baik dalam uji daya lengket. F3 yang memiliki variasi komposisi ekstrak secang 0,5 gr dan beeswax 4 gr memiliki konsistensi krim lebih padat, sehingga daya lekat juga tinggi.

\section{Uji Daya Proteksi}

Pengujian daya proteksi bertujuan untuk mengetahui kemampuan krim dalam melindungi kulit dari infeksi faktor luar seperti sinar matahari dan polusi.

Tabel 7. Hasil Uji Proteksi Krim

\begin{tabular}{|l|c|c|c|c|c|c|c|}
\hline For & \multirow{2}{*}{$\begin{array}{l}\text { Repli } \\
\text { mu }\end{array}$} & kasi & \multicolumn{7}{|c|}{ Waktu ke } \\
\cline { 3 - 8 } & & $\begin{array}{c}15 \\
\text { dtk }\end{array}$ & $\begin{array}{c}30 \\
\text { dtk }\end{array}$ & $\begin{array}{c}45 \\
\text { dtk }\end{array}$ & $\begin{array}{c}60 \\
\text { dtk }\end{array}$ & $\begin{array}{c}3 \\
\mathrm{mnt}\end{array}$ & $\begin{array}{c}5 \\
\mathrm{mnt}\end{array}$ \\
\hline F1 & 1 & + & + & + & + & + & + \\
\hline & 2 & + & + & + & + & + & + \\
\hline & 3 & + & + & + & + & + & + \\
\hline F2 & 1 & + & + & + & + & + & + \\
\hline & 2 & + & + & + & + & + & + \\
\hline & 3 & + & + & + & + & + & + \\
\hline F3 & 1 & + & + & + & + & + & + \\
\hline & 2 & + & + & + & + & + & + \\
\hline & 3 & + & + & + & + & + & + \\
\hline
\end{tabular}

Berdasarkan uji daya proteksi krim menunjukkan adanya perubahan pada setiap replikasi. Hal ini terjadi dikarenakan sifat dari secang yang tidak stabil dan mudah teroksidasi.

\section{KESIMPULAN}

Formula krim variasi ekstrak secang dan beeswax Sumbawa yang disukai oleh panelis berdasarkan aspek organoleptik adalah F3 pada aspek bentuk dan warna. Dan pada pengujian daya lengket F3 juga memiliki daya lekat yang baik.

Formulasi F3 memiliki komposisi bahan ekstrak secang sebanyak 0,5 gr dan beeswax Sumbawa sebanyak 4 gr. 


\section{Saran}

Pengujian krim dalam efektivitas daya hambat terhadap bakteri penyebab jerawat baik secara in vitro maupun in vivo dapat dilaksanakan guna menambah kekuatan pada produk yang dihasilkan.

\section{REFERENSI}

Christina, I. 2009. Optimasi Suhu Pencampuran dan Kecepatan Putar pada Proses Formulasi Krim Sunscreen Ekstrak Kering Teh Hijau (Camelia sinensis L.) dengan Aplikasi Desain Faktorial. Skripsi. Fakultas Farmasi. Universitas Sanata Dharma. Yogyakarta.

Erungan, A.C., Sri, P., \& Syeni, B.D. (2009).Aplikasi Keraginan Dalam Pembuatan Skin Lation. Bogor. Departemen Teknologi Dan Hasil Perairan Fakultas Perikanan Dan Ilmu Kelautan Institut Pertanian Bogor

Hispratin, Y., dan Nuwarda, R.F. 2018. Perbedaan Emulsi dan Mikroemulsi Pada MinyakNabati. Jurnal Farmaka Suplemen. Vol 16 no 1.

Juwita, A. P., Yamlean, P. V. Y dan Edy, H. J. 2013. Formulasi Krim Ekstrak Etanol DaunLamun (Syringodium isotifolium), Jurnal Ilmiah Farmasi UNSRAT, 2(2).

Liebermen, H, A., Ringger, M. M., and Banker, G. S.,1996. Pharmaceutical Dosage Form, Second edition. 308,400,408, Marcel Decker Inc. New York.

Lubis, E, S., Lubis.,L.S dan Reveny ,J., 2012. Pelembab Kulit Alami dari Sari Buah Jeruk Bali (Citrus maxima maxima (burm)
Osbeck), Jurnal of pharmaceutics and pharmacology. Fakultas Farmasi, Universitas Sumatera Utara, Medan. Hal; 107

Rizky, A,W., Latifa., dan Winami, P. 2013. Formulasi Krim Ekstrak Lidah Buaya (Aloe vera) Sebagai Alternatif Penyembuhan Luka Bkar. Indonesia Journal of Chemical Science.

Safitri, N. A.,Puspita, O.K., Yunita, V. Optimasi Formula Sediaan Krim Ekstrak Stroberi (Fragaria $x$ ananassa) sebagai Krim Anti Penuaan. Majalah Kesehatan FKUB. Vol 1 No 4 .235-246. Universitas Brawijaya

Sharon, N., Anam, S., dan Yuliet,. 2013. Formulasi Krim Antioksidan Ekstrak Etanol Bwang Hutan (Eleutherine parmifolia L., Merr). Jurnal of Natural Science Fakultas Farmasi MIPA, Universitas Tadulako., Vol 2 (3) : 111-122.

Syamsuri.2006. Farmasetika Dasar dan Hitungan Farmasi. Penerbit Buku Kedokteran EGC. Jakarta

Tranggono, I.R \& Latifah, F. (2007).Buku Pegangan Ilmu Pengetahuan Kosmetik. PT. Gramedia Pustaka Utama. Jakarta.

Yulyuswarni. 2019. Formulasi Ekstrak Kayu Secang (Caesalpinia sappan L) dengan HPMC sebagai Gelling Agent. Jurnal Analis Farmasi. Vol. 4. No. 1. 66-72. Poltekkes Tanjungkarang.

Zharandont, P. 2015. Pengaruh Warna Bagi Suatu Produk dan Psikologi Manusia. Desain Produk. Fak.Industri Kreatif. Universitas Telkom. Jakarta. 